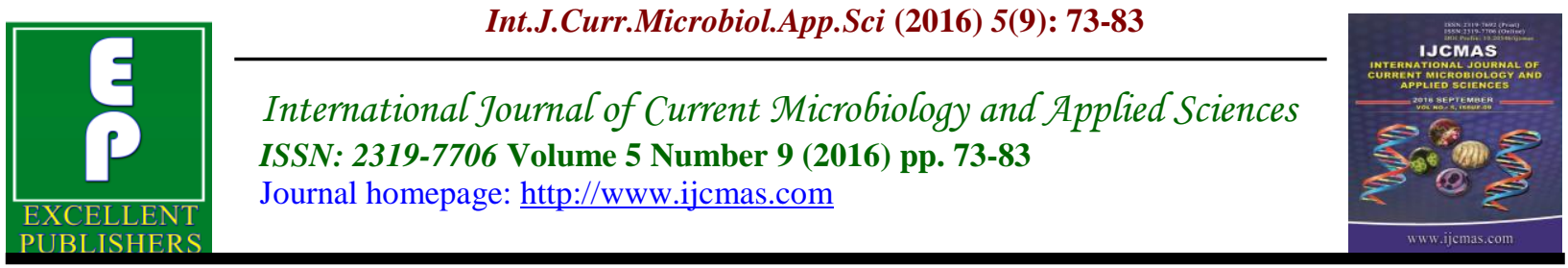

Original Research Article

http://dx.doi.org/10.20546/ijcmas.2016.509.009

\title{
Prevalence of Pseudomonas aeruginosa and its Antibiotic Susceptibility Pattern to Restraint Hospital Acquired Infection
}

\author{
Manish Pokra*, Smariti Pundir, Dileep Kumar Sharma, \\ Harsha Rani Verma, Jyoti Rana and Pushpa Mehta
}

Department of Microbiology, Jhalawar Medical College, Jhalawar, India

*Corresponding author

Keywords

Pseudomonas aeruginosa, Antibiotic Susceptibility Pattern.

\section{Article Info}

Accepted:

08 August 2016

Available Online:

10 September 2016

\section{A B S T R A C T}

Within the genus of Pseudomonas, $P$. aeruginosa is most frequently associated with human infections. Pseudomonas aeruginosa is regarded as an opportunistic pathogen, primarily causing nosocomial infections in immunocompromised patients. The bacterium is metabolically versatile bacterium that can cause a wide range of severe opportunistic infections in patients with compromised natural defences and serious underlying medical conditions. These infections are characterized by an intense neutrophilic response resulting in significant damage to host tissues and often exhibit resistance to antibiotics leading to mortality. Treatment of persistent infections is additionally hampered by adaptive resistance, due to the growth state of the bacterium in the patient including the microorganism's ability to grow as a biofilm. An array of $P$. aeruginosa virulence factors counteract host defences and can cause direct damage to host tissues or increase the bacterium's competitiveness. Treatment of infectious diseases becomes more challenging with each passing year. Given the severity of $P$. aeruginosa infections and the limited antimicrobial arsenal with which to treat them, finding alternative prevention and treatment strategies is an urgent priority. Pseudomonas aeruginosa being the major cause of human illness particularly in hospitalized patients and lack of information on the prevalent types responsible for various infections in this area of Rajasthan, prompted us to undertake the study. The study is done between july 2015 to june 2016 in a Tertiary care hospital of Jhalawar district to find the prevalence and pattern of antibiotic susceptibility of $P$. aeruginosa.

\section{Introduction}

Known for many years to be a cause of serious wound and surgical infections, but often regarded as a secondary or opportunistic invader rather than a cause of primary infection in healthy tissues, Pseudomonas aeruginosa has now clearly emerged as a major nosocomial pathogen in immunocompromised and debilitated patients, as well as in cystic fibrosis patients (Pier et al., 2005). P. aeruginosa has always been considered to be a difficult target for antimicrobial chemotherapy. However, the complete sequencing of a wild-type $P$. aeruginosa strain, achieved in 2000, has 
provided a great deal of useful information, concerning not only its pathogenicity, but also its potential for resistance (Stover $\mathrm{et}$ al., 2000). With 5570 open reading frames, the $P$. aeruginosa genome is among the largest genomes in the prokaryotic world, and encodes an unusually high proportion of proteins involved in regulation, transport and virulence functions, which may explain the high versatility and adaptive capacity of this species. In addition, $0.3 \%$ of the total genes code for proteins involved in antimicrobial resistance. The genome is also highly flexible, with $10 \%$ of genes organised in 'pathogenicity islands', comprising variable genes coding for virulence factors, and with the ability to easily acquire large mobile genetic elements (integrons) encoding resistance genes (Kipnis et al., 2006; Woods, 2004; Normark et al., 2002). The large size and the complexity of this genome is probably the basis for the capacity of $P$. aeruginosa to not only thrive in diverse environments and to infect a large variety of body sites, but also to resist (intrinsically or after acquisition of the necessary genes) a large number of antimicrobial agents. Pseudomonas aeruginosa has become an important cause of gram-negative infection, especially in patients with compromised host defense mechanisms. It is the most common pathogen isolated from patients who have been hospitalized longer than 1 week, and it is a frequent cause of nosocomial infections. Pseudomonal infections are complicated and can be life-threatening. The Gram-negative bacterium Pseudomonas aeruginosa is an opportunistic pathogen that normally inhabits the soil and surfaces in aqueous environments. Its adaptability and high intrinsic antibiotic resistance enable it to survive in a wide range of other natural and artificial settings, including surfaces in medical facilities. Serious $P$. aeruginosa infections are often nosocomial, and nearly all are associated with compromised host defenses such as in neutropenia, severe burns, or cystic fibrosis (Lyczak et al., 2000). Therapeutic options are increasingly limited due to the continued emergence and spread of antimicrobial resistant strains; as a result, $P$. aeruginosa infections demonstrate high morbidity and mortality. In the United States, $P$. aeruginosa is among the most common hospital pathogens and is the second most common pathogen isolated from patients with ventilator-associated pneumonia.

In the hospital, $P$. aeruginosa can be isolated from a variety of sources, including respiratory therapy equipment, antiseptics, soap, sinks, mops, medicines, and physiotherapy and hydrotherapy pools (Pollack, 1995). Community reservoirs of this organism include swimming pools, whirlpools, hot tubs, contact lens solution, home humidifiers, soil and rhizosphere, and vegetables (Harris et al., 1984; Pitt, 1998). This organism shows a remarkable capacity to resist antibiotics, either intrinsically (because of constitutive expression of blactamases and efflux pumps, combined with low permeability of the outermembrane) or following acquisition of resistance genes (e.g., genes for b lactamases, or enzymes inactivating aminoglycosides or modifying their target), overexpression of efflux pumps, decreased expression of porins, or mutations in quinolone targets.Worryingly, these mechanisms are often present simultaneously, thereby conferring multiresistant phenotypes. Although less frequent, class A extended-spectrum $\beta$ lactamases have also been detected in strains of $P$. aeruginosa and have included enzymes from the TEM, SHV, CTX-M, PER, VEB, GES, and IBC families (Castanheira et al., 2004; Danel et al., 1995; Mavroidi et al., 2001; Nordmann et al., 1994; Poirel et al., 
2001; Woodford et al., 2008). Extendedspectrum $\beta$-lactamases from the class $D$, OXA-type enzymes have also been encountered within $P$. aeruginosa (Naas et al., 1999; Philippon et al., 1997).

This organism survives in various environments in nature and in homes and hospitals. Because of the ubiquitous nature of Pseudomonas aeruginosa, transmission of this organism to humans can occur in variety of ways. It is physiologically versatile and flourishes as a saprophyte in warm moist situations in the human environment, including sink, drains, respirators, humidifiers and disinfectant solutions. Pseudomonas fluorescens, Pseudomonas putida, Pseudomonas stutzeri also are environmental inhabitants but they are much less commonly found in clinical specimens than is Pseudomonas aeruginosa. The other Pseudomonads and Brevundimonas spp. also are environmental organisms. Because they are rarely encountered in patient specimens, the mode of transmission to humans remains uncertain.

Isolation of Pseudomonas aeruginosa from healthy carriers or environmental sites is significant only when there is a risk of transfer to compromised patient, e.g. by nurses' hands or via respirators.

Normally, the human faecal carrier rate for Pseudomonas aeruginosa is less than $10 \%$; however, carrier rates increase with the length of stay of patients in hospital, reaching 30\% after 3 week, and this represents a distinct risk of endogenous infection. Faecal isolation frequencies of Pseudomonas aeruginosa increase dramatically in patients in hospital (rates up to $60 \%$ ), 24 and are closely correlated with the length of stay (Shooter et al., 1969). Of the species in these two genera Pseudomonas aeruginosa is the most thoroughly studied with regard to infections in human. Although this organism is an environmental inhabitant, it is also very successful opportunistic pathogen. It produce an over whelming infections which is due to an arsenal of virulence factors. Many extra cellular virulence factors secreted by Pseudomonas aeruginosa have been shown to be controlled by a complex regulatory circuit involving cell-tocell signalling system that allow the bacteria to produce these factors in a co-ordinated, celldensity dependant manner (Passador et al., 1995). Virulence determinants on pathogenic Pseudomonas aeruginosa : Adhesin fimbria ( $\mathrm{N}$. methyl-phenylalanine pilli), polysaccharide capsule (glycocalyx), alginate slime (biofilm). Invasins-elastase, alkaline protease, hemolysins (phospholipase, lecithinase), cytotoxin (leukocidin), siderophores and siderophore uptake system, Pyocyanin-diffusible pigment. Motility/chemotaxis flagella. Toxinsexoenzyme S, exotoxin A, lipopolysaccharide. Antiphagocytic surface properties-capsule, slime layer LPS. Defense against serum bactericida reaction-slime layer, capsule, protease enzymes, LPS. Defense against immune responses capsule, slime layers, protease en- zymes. Genetic attributes-genetic exchange by transduction and conjugation, inherent drug resistance, $\mathrm{R}$ factors and drug resistance plasmids.

In patients with no clinical evidence of infection, isolation of Pseudomonas aeruginosa, particularly in association with other resistant organisms such as Candida, can be a consequence of selection by antibiotic therapy and of little direct clinical relevance.

Infections due to Pseudomonas aeruginosa are seldom encountered in healthy adults but in the last two decades the organism has become increasingly recognized as the aetiological agent in a variety of serious 
infections in hospitalized patients with impaired immune defences including human immunodeficiency virus infection (O'Donnell et al., 1993). Colonization is often iatrogenic and associated with prior instrumentation e.g. catheterization, tracheostomy, etc. Pseudomonas aeruginosa is most feared cause of corneal ulceration, hence great care must be taken in maintenance and cleaning of contact lenses. Despite the emphasis on caution in assessing the clinical significance of Pseudomonas aeruginosa, there are undoubtedly occasions when serious infections occur. Panophthalmitis can result in partial blindness or loss of an eye. The organism is the major cause of malignant otitis media. Endocarditis and septicaemia caused by Pseudomonas aeruginosa is relatively rare but carries a mortality rate exceeding $70 \%$ in patients compromised by severe burns, cancer or drug addiction. The most significant pathogenic role for Pseudomonas aeruginosa at present is in the chronic debilitating pulmonary infections due to mucoid variants that are now the major cause of death in patients with cystic fibrosis. Even with the variety of potential virulence factors discussed; Pseudomonas aeruginosa remains an opportunistic pathogen that requires compromised host defenses to establish infection.

In normal, healthy host, infection is usually associated with events that disrupt or bypass protection provided by epidermis. The result is infections of the skin, bone, heart or eye. Pseudomonas aeruginosa is a notable cause of nosocomial infections of respiratory and urinary tract, wounds, blood stream, and even the central nervous system. For immunocompromised patients, such infections are often serious and frequently life-threatening. Pseudomonas aeruginosa shows high level of intrinsic resistance to a number of structurally unrelated antimicrobial agents and these results in increased illness, deaths, and health care cost.

The virtual nonexistence of antibiotic policies and guidelines in our country to help clinicians make rational choices with regard to antibiotic treatment is a major driver of the emergence and spread of multidrug resistance in India. Regular monitoring and documentation of resistance is therefore crucial in developing strategies to control infections due to these bacteria in patients admitted particularly in intensive care units. Assessment of the significance of a particular episode or outbreak of Pseudomonas aeruginosa infection, and selection of the most appropriate management procedures, require knowledge and appreciation of both the organism and the host. This can be achieved by consultations between microbiologist and clinician that take account of the patient's clinical status, the factors responsible for susceptibility to infection and any virulence factor exhibited by the particular strain of the organism.

\section{Material and Methods}

\section{Collection of specimens}

Clinical specimens viz. urine, blood, pus, CSF, fluids and aspirates would be collected aseptically, from patients of Jhalawar medical college and attached hospital.

\section{Processing in laboratory}

Specimens would be streaked on preincubated MacConkey's agar and blood agar plates within $5 \mathrm{hrs}$ of sample collection and Would be kept under aerobic incubation at $37^{\circ} \mathrm{C}$ for $24-48 \mathrm{hrs}$ and 72 hours for blood. Colony isolates would be further confirmed by colony morphology on MacConkey's agar, Blood agar,Pigment formation,Gram staining and Oxidase test as per standard 
guidelines.P.aeruginosa were isolated and identified by conventional methods. The antimicrobial susceptibility testing was performed by Kirby-Bauer disc diffusion method. The clinical and specimen distribution properties of P.aeruginosa were evaluated based on their resistance.

\section{Confirmation, identification, Virulence factor production}

Gram-negative rod

Oxidase-positive

Typical smell (fruity grape-like odor)

Recognizable colony morphology

On blood or chocolate agar appears as large colonies with metallic sheen, mucoid, rough, or pigmented (pyocyanin) and often $\beta$-hemolytic.

On MacConkey, appear as lactose-negative with green pigmentation or metallic sheen.

\section{Result and Discussion}

Pus, tracheal aspirates and urine were important sources of P.aeruginosa isolation in ICU and non ICU in patients. Almost 150 samples were taken, out of which 35 were of $P$. aeruginosa. Resistance rates of Pseudomonas varied with the antibiotics and the high resistance observed was related to the increased use of broad spectrum antibiotics. As per result of study P.aeruginosa were most susceptible to aminoglycosides (Tobramycin-66\%, Netilimicin-54\%, Gentamicin-54\%, Amikacin$45 \%$ ) followed by fluoro-quinolones (Norfloxacin - 4 9\%, Ciprofloxacin- 18\%) and Carbapenems (Meropenem-24\%, Imipenem-21\%). Piperacillin-tazobactum was almost $24 \%$ susceptible and
Doxycycline, Ceftriaxone, Nitrofurantoin, Azithromycin were among least susceptible.

Resistance to antimicrobial agents is an increasing public health threat (National Nosocomial Infection Surveillance System, 2004). It limits therapeutic options and leads to increased mortality and morbidity (Cosgrove et al., 2003). Given the increasing resistance rates in $P$. aeruginosa, multidrug resistance can be expected to become more prevalent in many hospitals. We conducted this study to better understand the individual risk factors for having MDR $P$. aeruginosa and to examine the consequences of its occurrence. Multidrug resistance P.aeruginosa is on the rise especially in nosocomial infections.

Hence rigorous monitoring of MDR strains, restriction of inappropriate use of antimicrobial agents and adherence of infection control practices should be emphasized to delay the emergence of clinically significant MDR-P. aeruginosa. For his reason epidemiological studies on the prevalence and antimicrobial susceptibility pattern of resistant isolates in different geographical settings would provide useful information to guide clinicians in their choice of therapy and to contribute to the global picture of antimicrobial resistance. Treatment of infectious diseases becomes more challenging with each passing year. Continued increases in immunosuppressed/ compromised patient populations and the evolutionary advantage of bacteria to rapidly mutate and adapt to antibacterial/biocide threats in their environment make the treatment of infectious diseases a serious challenge. This is especially true for the opportunistic pathogen $P$. aeruginosa and its ability to develop a multidrug-resistant phenotype. 
Table.1 $(32,33,34,35,36,37,38)$

Rates of antibacterial resistance among $P$. aeruginosa isolates from hospitals and ICUs

$$
\% \text { of strains exhibiting resistancea }
$$

\begin{tabular}{|c|c|c|c|c|c|c|c|c|}
\hline $\begin{array}{l}\text { Antibioti } \\
\text { c }\end{array}$ & $\begin{array}{l}\text { Hospit } \\
\text { al } \\
\text { study, } \\
2006(n \\
=606) \\
(\underline{211})\end{array}$ & $\begin{array}{l}\text { Hospit } \\
\text { al } \\
\text { study, } \\
2005(n \\
=589) \\
(\underline{\underline{212})}\end{array}$ & $\begin{array}{l}\text { Hospit } \\
\text { al } \\
\text { study, } \\
2002(n \\
= \\
9,896) \\
(\underline{54)}\end{array}$ & $\begin{array}{l}\text { ICU } \\
\text { study, } \\
2002(n \\
=951) \\
(\underline{178})\end{array}$ & $\begin{array}{l}\text { ICU } \\
\text { study, } \\
2000-2 \\
002(n \\
\geq \\
7,500) \\
(\underline{95})\end{array}$ & $\begin{array}{l}\text { Hospit } \\
\text { al } \\
\text { study, } \\
2001 \\
(n \geq \\
2,157) \\
(\underline{99})\end{array}$ & $\begin{array}{l}\text { ICU } \\
\text { study, } \\
2001(n \\
\geq 543) \\
(\underline{99)}\end{array}$ & $\begin{array}{l}\text { Hospit } \\
\text { al } \\
\text { study, } \\
2000(n \\
=882) \\
(\underline{100})\end{array}$ \\
\hline
\end{tabular}

$(\beta-$

Lactams)

Cefepime

Ceftazidi

6

$\begin{array}{lll}5 & 9 & 25\end{array}$

12

8

10

me

13

10

13

19

17

9

9

13

Piperacilli

11

9

11

10

14

8

13

tazobacta

$\mathrm{m}$

\section{Aztreona}

$\mathrm{m}$

Imipenem

Meropene

$\mathrm{m}$

32

(Fluoroqui nolones)

\begin{tabular}{|c|c|c|c|c|c|c|c|c|}
\hline $\begin{array}{l}\text { Ciprofloxa } \\
\text { cin }\end{array}$ & 21 & 22 & 35 & 32 & 33 & 26 & 25 & 25 \\
\hline $\begin{array}{l}\text { Levofloxa } \\
\text { cin }\end{array}$ & 22 & 22 & & 34 & 32 & 27 & 25 & 27 \\
\hline \multicolumn{9}{|l|}{$\begin{array}{l}\text { (Aminogly } \\
\text { cosides) }\end{array}$} \\
\hline Amikacin & & & 5 & 10 & & 4 & 3 & \\
\hline $\begin{array}{l}\text { Tobramyc } \\
\text { in }\end{array}$ & 8 & 10 & 12 & 16 & & & & \\
\hline $\begin{array}{l}\text { Gentamici } \\
\mathrm{n}\end{array}$ & 12 & 12 & 16 & & 22 & 15 & 15 & 14 \\
\hline
\end{tabular}



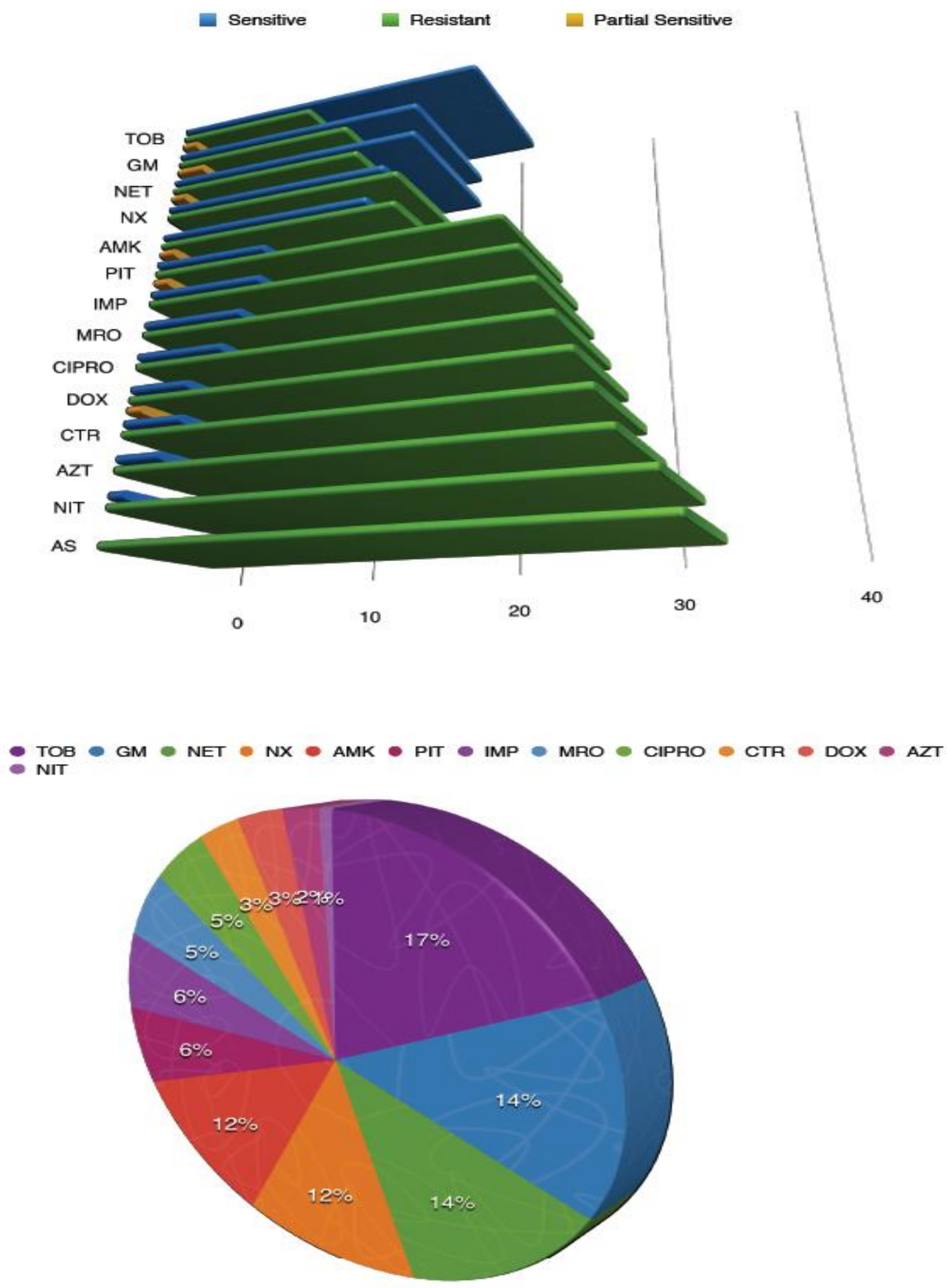

OVERALL SUSCEPTIBILITY OF ANTIBIOTIC WHEN COMPARED AMONG THEMSELVES 
Although the potential import of resistance mechanisms on mobile genetic elements is a continuing threat, perhaps the most difficult challenge we face with $P$. aeruginosa is its ability to rapidly develop resistance to multiple classes of antibiotics during the course of treating a patient. The chromosomal AmpC cephalosporinase, the outer membrane porin $\mathrm{OprD}$, and the multitude of efflux pumps are particularly relevant to this therapeutic challenge, and the discussion presented in this review highlights the complex mechanisms and pathways by which $P$. aeruginosa regulates and/or coregulates their expression. As the pipeline of new drugs achieving FDA approval continues to diminish, it is critical that we look for novel strategies to combat the threat of antibacterial resistance. One potential strategy is to target the regulation of bacterial resistance mechanisms as a pathway to enhance the potency of available drugs and, perhaps, restore the efficacy of available drugs. In addition to the development of direct inhibitors of resistance mechanisms, i.e., $\beta$-lactamase inhibitors, another strategy is to target the regulation of gene expression. Although a great deal of knowledge has been gained toward understanding the mechanisms by which $P$. aeruginosa regulates AmpC, OprD, and efflux pumps, it is clear that we have a long road ahead and have much to learn about how this resourceful pathogen coregulates different resistance mechanisms to meet the antibacterial challenges it faces.

MDR has usually been described as developing in a susceptible strain of $P$. aeruginosa exposed sequentially to various antibiotic agents (Carmeli et al., 1999) ICU stay had been found in previous studies to be an important risk factor for acquisition of resistant organisms, and the SCENIC study reported that half of the patients hospitalized in ICUs acquired a nosocomial infection
(Haley et al., 1980) Moreover, the intensity of selection pressure by broad-spectrum antibiotics is high in the ICU. The care of bedridden patients also requires intensive contact with healthcare providers who serve as the vector for transmission of these MDR bacteria. Treatment with multiple antibiotic agents, as described previously for other resistant organisms (Gould, 1994; Jarvis, 1992). The limited means of effectively treating MDR $P$. aeruginosa infections led to performing more surgery and other procedures (debridement, amputation, and removal of prostheses) among the study patients in order to eradicate the source of infection. Indeed, in the subgroup of patients for whom the nidus of infection could be removed by these procedures, morbidity and mortality were not increased, in contrast to their counterparts, for whom curative surgery was not an option. Thus, our findings confirm the results of a previous study (Harris et al., 1999) that reported that MDR $P$. aeruginosa was associated with adverse outcomes and that these outcomes are even worse when the nidus of infection cannot be removed surgically.

In conclusion, this analytic study highlights the complex epidemiology of MDR $P$. aeruginosa in hospitals. These infections are likely to affect critically ill patients who require intensive care and treatment with multiple antibiotic agents. Infection with MDR $P$. aeruginosa is associated with adverse clinical outcome, and strict isolation of patients infected with MDR microorganisms and judicial use of antibiotics should be emphasized in order to prevent the spread of MDR P. aeruginosa.

\section{Acknowledgement}

I have taken efforts in this project. However, it would not have been possible without the kind support and help of many individuals 
and organization. I would like to extend my sincere thanks to all of them. I am highly indebted to Dr. Pushpa Mehta, HOD Department of Microbiology for their guidance and constant supervision as well as for providing necessary information regarding the project $\&$ also for their support in completing the project. I would like to express my gratitude towards my parents \& member of medical college for their kind cooperation and encouragement which help me in completion of this project. I would like to express my special gratitude and thanks to Dr. Dileep Sharma, Asst. Prof. Depp. of Microbiology, for giving me such attention and time. My thanks and appreciations also go to my colleague in developing the project and people who have willingly helped me out with their abilities.

\section{References}

Bergmans, D. 1998. Cross-colonisation with Pseudomonas aeruginosa of patients in an intensive care unit. Thorax, 53: 1053-1058.

Betty, A., Forbes, Daniel, F.S., Alice, S.W. Bailey and Scott's Diagnostic Microbiology, 12th Edi. Mosbey Elsevier 2007.

Carmeli, Y., N. Troillet, G. Eliopoulos, and M. H. Samore. 1999. Emergence of antibiotic-resistant Pseudomonas aeruginosa: comparison of risks associated with different antipseudomonal agents. Antimicrob. Agents Chemother., 43: 1379-1382. [PMC free article]

Castanheira, M., R.E. Mendes, T.R. Walsh, A.C. Gales, and R.N. Jones. 2004. Emergence of the extended-spectrum beta-lactamase GES-1 in a Pseudomonas aeruginosa strain from Brazil: report from the Sentry antimicrobial surveillance program. Antimicrob. Agents Chemother., 48: 2344-2345.

Clark, T.J. inc .com/ bacterial -disease /
Pseudomonas- aeruginosa.htm.

Collee, J.G., Diguid, J.P., Fraser, A.G. 1996. Pseudomonas, Stenotrophomonas, Burkholderia. In:Mackie and McCartney practical Medical Microbiology.14 th ed. (Churchill Livingstone, Edinburgh) 1996:413-24

Cosgrove, S.E., and Y. Carmeli. 2003. The impact of antimicrobial resistance on health and economic outcomes. Clin. Infect. Dis., 36: 1433-1437.

Danel, F., L.M. Hall, D. Gur, H.E. Akalin, and D.M. Livermore. 1995. Transferable production of PER-1 beta-lactamase in Pseudomonas aeruginosa. J. Antimicrob. Chemother., 35: 281-294.

Dart, J.K.G., Seal, D.V. 1988. Pathogenesis and therapy of Pseudomonas aeruginosa Eye, 2: 46-55.

Flamm, R.K., Weaver, M.K,. Thornsberry, C., Jones, M.E., Karlowsky, J.A., Sahm, D.F. Antimicrob. Agents Chemother., 48(7): 2431-6.

Gould, I.M. 1994. Risk factors for acquisition of multi-drug resistant Gram-negative bacteria. Eur. J. Clin. Microbiol. Infect. Dis., Suppl. 1: 30-38.

Govan, J.R.W., Nelson, J.W. 1992. Microbiology of lung infection in cystic fibrosis. British Med. Bull., 48: 912930.

Haley, R.W., and R.H. Schachtman. 1980. The emergence of infection surveillance and control programs in US hospitals: a assessment, 1976. Am. J. Epidemiol., 111: 574-579.

Harris, A. A., L. Goodman, and S. Levin. 1984. Community-acquired Pseudomonas aeruginosa pneumonia associated with the use of a home humidifier. West. J. Med., 141: 521523.

Harris, A.D., C. Toress-Vierra, L. Ventakataraman, P.C. DeGirolami, M.H. Samore, and Y. Carmeli. 1999. Epidemiology and clinical outcomesof infections with multi-resistant Pseudomonas aeruginosa. Clin. Infect. Dis., 28: 1128-1133. 
Hidron, A.I., Edwards, J.R., Patel, J., Horan, T.C., Sievert, D.M., Pollock, D.A., Fridkin, S.K. 2008. National Healthcare Safety Network Team \& Partic- ipating National Healthcare Safety Network Facilities (2008) NHSN annual update: antimicrobial-resistant pathogens associ- ated with healthcare-associated infections: annual summary of data reported to the National Healthcare Safety Network at the Centers for Disease Control and Prevention, 20062007. Infect. Control Hosp. Epidemiol., 29: 996-1011.

Jarvis, W.R. 1992. Predominant pathogens in hospital infections. J. Antimicrob. Chemother., 29(Suppl. A): 19-24.

Jones, M.E., Draghi, D.C., Thornsberry, C., Karlowsky, J.A., Sahm, D.F., Wenzel, R.P. Ann. Clin. Microbiol. Antimicrob., 29; (3):14.

Karlowsky, J.A., Kelly, L.J., Thornsberry, C., Jones, M.E., Evangelista, A.T., Critchley, I.A., Sahm, D.F. 2002. Int. J. Antimicrob. Agents, 19(1): 21-31.

Karlowsky, JA.,. Draghi, D.C., Jones, M.E., Thornsberry, C., Friedland, I.R., Sahm, D.F. 2003. Antimicrob. Agents Chemother.,; 47(5):1681-8.

Kipnis, E., Sawa, T., Wiener-Kronish, J. 2006. Targeting mecha- nisms of Pseudomonas aeruginosa pathogenesis. Med. Mal. Infect., 36: 78-91.

Levison, M.E. 1977. Factors influencing colonization of the gastrointestinal tract with Pseudomonas aeruginosa, Pseudomonas aeruginosa: Ecological aspects and patient colonization, ed. Young VM, Raven Press, New York, 97-109.

Lyczak, J.B,. Cannon, C.L. \& Pier, G.B. 2000. Establishment of Pseudomonas aeruginosa infection: lessons from a versatile opportunist. Microbiol. Infect., 2: 1051-1060.

Mavroidi, A., E. Tzelepi, A. Tsakris, V. Miriagou, D. Sofianou, and L. S. Tzouvelekis. 2001. An integron associated beta-lactamase (IBC-2) from
Pseudomonas aeruginosa is a variant of the extended-spectrum betalactamase IBC-1. J. Antimicrob. Chemother., 48: 627-630.

Mesaros, N,. Nordmann, P., Ple siat, P., Roussel-Delvallez, M., Van Eldere, J., Glupczynski, Y., Van Laethem Y, Jacobs F, Lebecque, P., Malfroot, A., Tulkens, P.M. and Van, 2007. Pseudomonas aeruginosa: resistance and therapeutic options at the turn of the new millennium. Clin. Microbiol. Infect., 13: 560-578.

Naas, T., and P. Nordmann. 1999. OXA-type beta-lactamases. Curr. Pharm. Des., 5: 865-879.

National Nosocomial Infection Surveillance System. National Nosocomial Infection Surveillance (NNIS) System report, data summary from January 1992 through June 2004, issued October 2004. Am. J. Infect. Control, 32: 470485.

Neu, H.C. 1983. The role of Pseudomonas aeruginosa in infections. $J$. Antimicrobial Chemother., 11: Suppl B 1-13.

Nordmann, P., and T. Nass. 1994. Sequence analysis of PER-1 extendedspectrum beta-lactamase from Pseudomonas aeruginosa and comparison with class A beta-lactamases. Antimicrob. Agents Chemother., 38: 104-114.

Normark, B.H., Normark, S. 2002. Evolution and spread of anti- biotic resistance. $J$. Intern. Med., 252: 91-106.

O’Donnell, J.G., Sorbello, A.F., Condoluci, D.V., Barnish, M.J. 1993. Sinusitis due to Pseudomonas aeruginosa with human immuno deficiency virus infection. Clin. Infect. Dis., 16: 404406.

Obritsch, M.D., Fish, D.N., MacLaren, R., Jung, R. 2004. Antimicrob. Agents Chemother., 48(12):4606-10.

Passador, L., Iglewski, B.H. 1995. Quorum sensing and virulence gene regulation in Pseudomonas aeruginosa. In: Roth JA, editor. Virulence mechanisms of 
bacterial pathogens. 2nd ed. Washington, American Soc. Microbiol., p. 65- 78.

Philippon, L.N., T. Naas, A.T., Bouthors, V. Barakett, and P. Nordmann. 1997. OXA-18, a class D clavulanic acidinhibited extendedspectrum betalactamase from Pseudomonas aeruginosa. Antimicrob. Agents Chemother., 41: 2188-2195.

Picao, R.C., L. Poirel, A.C. Gales, and P. Nordmann. 2009. Further identification of CTX-M-2 extended-spectrum betalactamase in Pseudomonas aeruginosa. Antimicrob. Agents Chemother., 53: 2225-2226.

Pier, G., Ramphal, R. 2005. Pseudomonas aeruginosa. In: Mandell G, Bennett J, Dolin R, eds, Principles and practice of infec- tious diseases. Philadelphia, PA: Elsevier Churchill Liv- ingstone, 25872615.

Pitt, T.L. 1998. Pseudomonas, Burkholderia, and related genera, p. 1109-1138. In B. I. Duerden (ed.), Microbiology and microbial infections, vol. 2. Oxford University Press Inc., New York, NY.

Poirel, L., V.O. Rotimi, and E.M. Mokaddas. 2001. VEB-1-like extended spectrum beta-lactamases in Pseudomonas aeruginosa, Kuwait. Emerg. Infect. Dis., 17:468-470.

Pollack, M. 1995. Pseudomonas aeruginosa, p. 1820-2003. In G. L. Mandell, R. Dolan, and J. E. Bennett (ed.), Principles and practices of infectious diseases. Churchill Livingstone, New York, NY.

Rhomberg, P.R., Deshpande, L.M., Kirby, J.T., Jones, R.N. 2007. Diagn. Microbiol. Infect. Dis., 59(4):425-32.

Rhomberg, P.R., Jones, R.N. 2007. Diagn. Microbiol. Infect. Dis., 57(2):207-15.

Shooter, R.A., Cooke, E.M. et al., 1969. Food and medicament as possible sources of hospital strains of Pseudomonas aeruginosa, Lancet, I: 1227-9.

Stover, C.K., Pham, X.Q., Erwin, A.L. et al. 2000. Complete genome sequence of Pseudomonas aeruginosa PA01, an opportun- istic pathogen. Nature, 406: 959-964.

Weldhagen, G.F., L. Poirel, and P. Nordmann. 2003. Ambler class A extendedspectrum beta-lactamases in Pseudomonas aeruginosa: novel developments and clinical impact. Antimicrob. Agents Chemother., 47: 2385-2392.

Woodford, N., J. Zhang, M.E. Kaufmann, S. Yarde, M.D.M. Tomas, C. Faris, M.S. Vardhan, S. Dawson, S.L. Cotterill, and D.M. Livermore. 2008. Detection of Pseudomonas aeruginosa isolates producing VEB-type extended-spectrum beta-lactamases in the United Kingdom. J. Antimicrob. Chemother., 62: 12651268.

Woods, D.E. 2004. Comparative genomic analysis of Pseudo- monas aeruginosa virulence. Trends Microbiol., 12: 437439.

\section{How to cite this article:}

Manish Pokra, Smariti Pundir, Dileep Kumar Sharma, Harsha Rani Verma, Jyoti Rana and Pushpa Mehta. 2016. Prevalence of Pseudomonas aeruginosa and its Antibiotic Susceptibility Pattern to Restraint Hospital Acquired Infection. Int.J.Curr.Microbiol.App.Sci. 5(9): 73-83. doi: http://dx.doi.org/10.20546/ijcmas.2016.509.009 